\title{
Mit aktuellen wissenschaftlichen Fakten überzeugen
}

Über 100 Publikationen pro Jahr, rund 230 laufende und weit über 1000 bereits publizierte Studien: Fakten wie diese zeigen, dass Straumann auch in wissenschaftlicher Hinsicht zu den führenden Firmen in der Implantologie zählt. Seit 60 Jahren engagiert sich das Unternehmen in der Forschung. Pro Jahr fließen 5 bis $6 \%$ des NettoUmsatzes in die Entwicklung und Produkttestung. Dabei arbeitet das Unternehmen eng mit führenden Klinikern und Wissenschaftlern zusammen, um den klinischen Nutzen der Produkte nachzuweisen. So sind für das Unternehmen Implantat-Überlebensraten von 97 bis $99 \%$ über 10 Jahre dokumentiert (Buser et al. Clin Implant Dent Relat Res. 2012). Diese Fakten überzeugen die Anwender, wie eine weitere beeindruckende Zahl belegt: Weltweit wurden bisher über 14 Millio- nen Straumann-Implantate gesetzt. Mehr Informationen unter http://www.straumann.de/wissenschaft

Nach einer Pressemitteilung der

Straumann GmbH, Freiburg

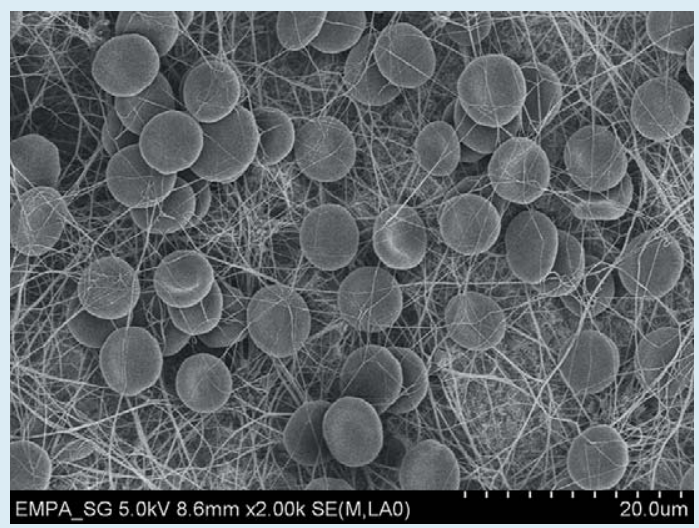

